\title{
Taking Responsibility for Industrial Digitalization: Navigating Organizational Challenges
}

\author{
Linnéa Carlsson $^{1, * \mathbb{D}}$, Anna Karin Olsson ${ }^{1} \mathbb{D}$ and Kristina Eriksson ${ }^{2} \mathbb{C}$
}

1 School of Business, Economics and IT, University West, SE-461 86 Trollhättan, Sweden; anna-karin.olsson@hv.se 2 Department of Engineering Science, University West, SE-461 86 Trollhättan, Sweden; kristina.eriksson@hv.se * Correspondence: linnea.carlsson@hv.se

\section{check for}

Citation: Carlsson, L.; Olsson, A.K.; Eriksson, K. Taking Responsibility for Industrial Digitalization: Navigating Organizational Challenges. Sustainability 2022, 14, 866. https://doi.org/10.3390/su14020866

Academic Editors:

Koteshwar Chirumalla, Jessica Bruch, Anna Öhrwall Rönnbäck,

Alessandro Bertoni and

Anna Syberfeldt

Received: 26 November 2021

Accepted: 6 January 2022

Published: 13 January 2022

Publisher's Note: MDPI stays neutral with regard to jurisdictional claims in published maps and institutional affiliations.

Copyright: (c) 2022 by the authors. Licensee MDPI, Basel, Switzerland. This article is an open access article distributed under the terms and conditions of the Creative Commons Attribution (CC BY) license (https:// creativecommons.org/licenses/by/ $4.0 /)$.

\begin{abstract}
In this article, an employee perspective has been applied in aiming to explore how organizations face challenges and take responsibility for industrial digitalization, thus extending the research on the human-centric perspective in relation to Industry 4.0 technologies. To give emphasis to the human-centric perspective, the co-workership wheel was applied to identify and analyze data. The findings of an explorative longitudinal qualitative case study consisting of 35 in-depth interviews with informants from a manufacturing company were used. Additional data collection consisted of documents and project meetings. By applying a human-centric perspective, llessons learned from this case study show that taking responsibility for industrial digitalization is challenging and the importance of an adaptive organizational culture and a focus on learning and competence are crucial. We argue that the findings give useful implications for manufacturing organizations navigating the challenges of industrial digitalization to sense and seize the benefits of Industry 4.0 technologies.
\end{abstract}

Keywords: industrial digitalization; Industry 4.0 technologies; co-workership wheel; adaptive culture; learning; competence; manufacturing; human-centric

\section{Introduction}

Industrial digitalization is not driven mainly by technological development, but by digital strategies, often rooted in organizational culture [1], and no part of the organization is immune to its effects [2]. The growing interconnections between employees and Industry 4.0 (I4.0) technologies are modifying the conditions under which organizations must navigate, hence prompting organizational changes. I4.0 technologies include, for example, internet of things, robotics, big data analytics, and cloud manufacturing [3] often related to artificial intelligence solutions. Furthermore, manufacturing organizations also must respond to external demands of sustainable production [4]. In addition, manufacturing organizations' existing organizational structures and cultures need to be tailored to the desired outcomes of organizational capabilities and external sustainability demands [4-6] since industrial digitalization is challenging organizational structures and employees' actions [7]. Organizational structure herein refers to the allocation of tasks and responsibilities to employees and various degrees of centralization, hierarchy, and specialization within an organization [8]. Organizations need to be clear about why digitalization is important, when proper, and what initiatives are beneficial [9]. In turn, employees need to understand how to integrate and manage I4.0 technologies related to work and tasks, thus needing organizational approaches for learning and competence [3,10]. As such, it becomes essential to understand how organizations face challenges and are taking responsibility for industrial digitalization since it is an ongoing strategic issue for manufacturing organizations.

Recently, a more human-centric perspective has arisen as a response to the technocratic understanding of industrial digitalization; Industry 5.0 (I5.0) [11]. This perspective, with a strong focus on the organizational structure, culture, and employees' engagement and responsibility as drivers of industrial digitalization, is a contrast to the technocratic 
understanding and focus on key technologies. For instance, humans' interaction, critical thinking, and interpretation are described as important when facing challenges of industrial digitalization and new technologies [12,13]. This human-centric perspective emphasizes the need to acknowledge employee resistance, striving towards trust and learning as a solution for reaching sought efficiency. In doing so, it is argued to be a way of pairing human and machine to better navigate the elusiveness of industrial digitalization [11]. On top of that, it is argued that industrial digitalization is not dependent on the level of innovations or type of business. Rather, the basic prerequisites ought to be human behaviors, norms, and working routines on which the organization is built [14].

Organizational culture has been recognized as an important condition for enabling industrial digitalization given that it is a prerequisite for adaptability to changes [15]. Culture is here viewed as the weave that binds schemes, norms, beliefs, and routines together in an organization [16]. The organizational culture evolves over time and may be subject to internal or external change efforts; in this study, changes related to industrial digitalization. The organizational culture constitutes an interpretation pattern that helps employees, regardless of level, to understand situations in similar ways, prioritize in a similar fashion, and ultimately handle similar situations in a similar manner [16]. Adaptability is consequently a cultural trait which guides behaviors and processes that support appropriate responses to external and internal conditions, i.e., industrial digitalization. Notably, how effectively an organization can navigate industrial digitalization will represent the level of cohesiveness of the organization [17]. Hence, a human-centric perspective is vital.

To give emphasis to the human perspective, a co-worker approach is herein applied. The essence of the concept of co-workership is taking responsibility; other aspects are higher degrees of employee engagement, participation, inclusion and openness, trust, and influence $[18,19]$. Earlier research also emphasizes that employees need basic understanding of I4.0 technologies combined with the ability to communicate and work as a team [3]. In this regard, an adaptive culture is viewed as a mean of fostering engagement and commitment to industrial digitalization, both regarding managerial actions associated with adoption of I4.0 technologies and the encouragement of initiatives among employees [20].

Digital innovations often stem from grassroots initiatives, which allow for creativity, trial and error, and shop-floor experiments, etc. [21]. As such, it is not the I4.0 technologies that are in the epicenter of the change but the human relations, i.e., employees. Allowance for creativity, trial and error, and advocating experimentalism, employee engagement, and responsibility are all features of an adaptive culture [22]. This study is closely related to the concept of co-workership [19]. Moreover, this comes close to the discussion of what sets of capabilities are necessary to navigate industrial digitalization.

Consequently, following this reasoning, and the importance of understanding humans (employees) in relation to I4.0 technology applications, we argue the need to further explore human-centric perspectives in the era of I4.0. By applying an employee perspective, this study aimed to explore how organizations face challenges and take responsibility for industrial digitalization. The term employee is herein applied in a general sense to describe all co-workers of the organization. Given the above, the following research questions are addressed:

(i) How can challenges of industrial digitalization be understood through the perspectives of employees?

(ii) What are the implications of employees' perspectives when organizations are navigating the depicted challenges of industrial digitalization?

The article is structured as follows. In the first section, the theoretical framework is presented. Here, the organizational culture and change in the era of industrial digitalization are outlined. This section is followed by a presentation of the co-workership wheel, a means of understanding organizational change based on employees' initiatives and interpretations. After that, a longitudinal explorative case study is presented, including a description of the empirical case, method, and analysis. Lastly, the findings are presented and sorted following the theoretical framework of co-workership. To conclude, this paper discusses 
taking responsibility for industrial digitalization through an employee perspective and the implications for organizations to navigate industrial digitalization.

\section{Theoretical Framework}

\subsection{Organizational Culture and Change}

Earlier research often views "digitalization as a bundle of social, economic, and cultural changes" triggered by the increasing use and advance of I4.0 technologies [7]. I4.0 technologies are herein the collected term covering, e.g., automation, the internet of things, machine learning, and other advanced technologies increasingly practiced in contemporary manufacturing organizations [23]. As such, I4.0 technologies are the applied advanced technologies within the era of industrial digitalization, which manufacturing organizations must strategize. From a more business-oriented perspective, industrial digitalization is often viewed as a source of disruptions triggering strategic responses [24] and organizational changes [20]. In brief, academic literature is dominantly focused on specific aspects such as key technologies, and challenges and drivers of industrial digitalization. The largest gains of the introduction of I4.0 technologies are argued to be neutralized as large resistance towards the implementation among employees may follow [11]. It is argued that resistance stems from a lack of a human-centric perspective, e.g., the changes of social and cultural aspects. As such, some scholars suggest providing a holistic agenda [25] as it is essential to encompass the entire picture to achieve an overall view of digitalization [2]. It has also been highlighted that the aspects of gaining management support and understanding of the adoption of novel technologies are important for successful implementation [26], and how the organizational culture affects adaptability [17]. A holistic view is emphasized as vital when building strategic resilience and leading to organizational sustainability [27]. Thus, it is argued that the process of digitalization needs to manage structural changes and organizational barriers to progress [24].

It is important to understand the barriers to industrial digitalization. Thus, participatory actions should be aimed for among employees as well as offering opportunities for learning [18]. This entails that the organizational abilities to foster responsibility are a shared endeavor. However, employee participation and learning, including gaining or holding skills in how to face industrial digitalization, is not something that just happens through management declaration, but through organizational culture. Culture is the capability of an organization that preserves the know-how of adaption that has been arranged into a tacit knowledge "pattern of recipes for handing situations" [28]. The development of organizational capabilities helps an organization to modify or create new operational routines as organizations need to change [20].

Culture as a capability [29] is viewed as a stock of knowledge and serves as a scheme "that constraints what people do and a scheme of interpretations of how the doing is evaluated" [28] (p. 378). For example, recent research has discussed the connections between an organization's need to understand the relation between the culture and employees [30] to be able to navigate industrial digitalization. An open and engaging attitude towards technology-driven change has been argued to be crucial, as well as challenging [17].

Within an organization, the integration of human and technology perspectives, i.e., digital, and non-digital assets, must be bridged in innovative and sustainable ways, including a substantial redefinition of structural boundaries [17].

\subsection{The Concept of Co-Workership}

The employee is here viewed as an autonomous actor of the collective structure. Hence, the employee is understood as being an actor within the organization and not dependent; to be following someone's directions formally or informally or bound by hierarchical structures of the organization [31]. Thus, herein co-worker refers to all employees.

The concept of co-workership is also a way of depicting that management questions reside around structures and employees' attitudes towards the organization and its vision- 
based work. In this sense, co-workership is a concept of understanding organizational change based on employees' initiatives and prospects [32].

The co-workership wheel is a theoretical framework that characterizes co-workership through four thematic conceptual pairs (see Figure 1):

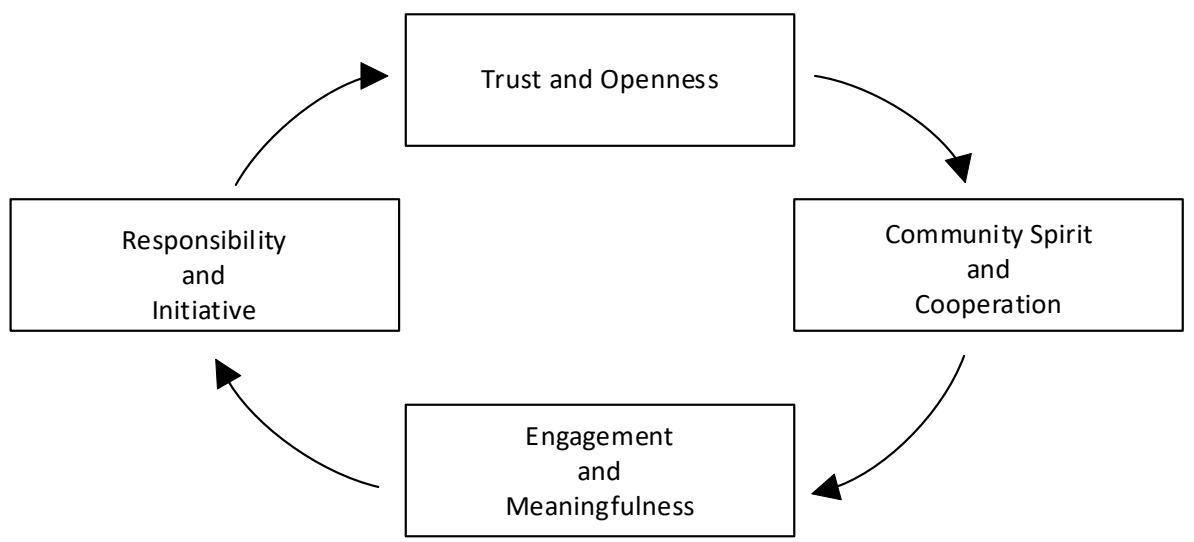

Figure 1. The co-workership wheel (see [16]).

\subsubsection{Trust and Openness}

Co-workership is in its essence about relationships, including work relationships. Trust is within all functional relationships a core ability. The ability is mainly manifested through open dialogues among constellations such as managers and workers, workers and workers, or workers and employers in general [16].

\subsubsection{Community Spirit and Cooperation}

Effective cooperation should transcend organizational borders, regardless of organizational structures or hierarchy professional roles, functions, or other barriers [16]. A part of the community spirit is the encouragement of learning with colleagues and by colleagues. However, it has been emphasized that organizations are struggling to address the missing digital competence [33]. This aspect of joint learning and knowledge exchange is highlighted as an important factor among employees when engaging in competence development initiatives [26,33].

\subsubsection{Engagement and Meaningfulness}

Beyond the commitment to the work itself, constructive co-workership requires a commitment to the organization. Such commitment is influencing the meaningfulness of the work [16]. The more an employee is engaged, the more one may mature in the task assigned, but also in the collective one belongs in. As such, responsibility becomes a question of allowance for commitment and constructiveness.

\subsubsection{Responsibility and Initiative}

Responsibility and action are closely linked, since those who feel responsible in a situation tend to be active and take initiative. One who feels responsibility also requires formal structure and routines to go through with initiatives. Responsibility strengthens initiative actions within an organization and may engage employees in organizational visions [16]. In addition, the ability to engage in initiatives and take responsibility is also a question of one having the competence needed to see and understand initiatives.

\subsection{Motivation for Theortical Framework}

Given the above the co-workership wheel describes the conditions necessary for constructive co-workership. When these conditions exist, they feed back a development process, e.g., during organizational change. The conditions thus become both conditions 
and outcomes of a constructive co-workership [16,19]. Increased openness and dialogue may strengthen the sense of community, which may promote cooperation and engagement in the organization, which in turn may strengthen the employees' sense of responsibility and willingness to take the initiative. If such exemplified approaches are shared within an organization, co-workership may be viewed as a part of the organizational culture. The culture, in turn, may help employees create a homogeneous understanding, prioritize similarly, and ultimately similarly handle challenges.

While some of these terms (initiative, engagement, and participation) have been used relative to industrial digitalization [9] and the strategic imperative [34], their usage here reflects the interest of how employees' perspectives may affect organizations navigating industrial digitalization. Earlier studies of Swedish manufacturing industry showed that as the number of I4.0 technologies increases within an industry, cooperation and social factors become more crucial, leading to a change in management being more distributed [35,36], and hence, becoming more inclusive and human-centric in organizational change.

\section{Methodology}

This research was designed as an explorative longitudinal case study, focusing on employees' interpretations of industrial digitalization. In order to embrace the elusiveness of industrial digitalization, a case study methodology was applied to study a phenomenon in its real context with its specific features $[37,38]$. This approach was favored as it gives allowance for in-depth study of employees' understandings and perspectives. Further, it helps explain how employees' perspectives may affect the organization's capability to navigate industrial digitalization successfully. The term employee is herein applied in a general sense to describe all co-workers of the organization. Hence, the chosen qualitative methodology is appropriate to grasp the human-centric perspective focusing on the four conceptual pairs within the co-workership wheel. To embrace the elusiveness of industrial digitalization a case study methodology was applied to study a phenomenon in its real context with its specific features $[37,38]$.

Early research shows that interpretations of technology are particularly influential because interpretations are established rapidly and are assimilated into work practices, organizational routines, and work habits, e.g., culture [13].

\subsection{Case Description and Data Collection}

The empirical setting of this case study was one large manufacturing organization in the Swedish energy sector, herein referred to as Alfa (a pseudonym), with seven production units. All seven units produce and sell original equipment in a local and global chain of production plants. Furthermore, Alfa is part of a larger global company with multiple manufacturing sites. Herein, if not stated otherwise, when referring to Alfa all seven production units are of concern.

The explorative case study began by creating a general understanding of Alfa's organization and production system arrangement. This was done through an initial case study to obtain a background understanding. We collected and analyzed production data to identify the data requirements for application of I4.0 technologies for production decision-making. The result from this initial case study gave an overall understanding of the added complexity of implementing novel technologies in an existing manufacturing facility with disparate production processes, complex production flow, older machinery, and much manual work. This in turn emphasized the human knowledge and involvement necessary to fully move into the era of I4.0 [12]. Further, the outcome indicated that there may be synergies between the effectiveness of the production system on the shop-floor level in relation to organization, management, and company culture. This became essential for designing the next part of the explorative longitudinal case study-emphasizing the importance of studying the holistic perspective of an organization to understand challenges through employees' perspectives of industrial digitalization. Hence, a strength of this initial case study was the combination 
of understanding the production flow, system, and processes in relation to management and organizational culture.

Moving forward, to obtain a holistic understanding of the case study, 35 interviews were conducted combined with two pilot interviews, nine partner meetings, and collection and reading of firm documents such as annual reports and strategic digitalization documents (see Table 1). Interviews were conducted by authors of this paper, except for six of the interviews that were performed together with one other researcher. This holistic approach served as a means for continuous validation and dissemination of findings during 2019-2021 to enhance the university-society research collaboration (see [39]).

Table 1. Overview of empirical data.

\begin{tabular}{cc}
\hline Material & Amount of Material \\
\hline Interviews & 35 informants \\
5 March 2019-24 June 2021 & 2 informants \\
Pilot interviews & \\
CEO & 9 meetings \\
Head of digitalization process & \\
Partner meetings; date & \\
16 October 2020 & \\
23 January 2020 & \\
12 February 2020 & \\
6 November 2020 & \\
4 December 2020 & \\
15 January 2021 & \\
8 June 2021 & \\
22 October 2021 & \\
23 November 2021 & \\
Documents & \\
Vision and policy documents &
\end{tabular}

To gain insight about the organization's size, business, and structure, two pilot interviews were held with one chief executive officer (CEO) and the head of the internal digitalization process. They were asked to foretell the business structure and hierarchy of functions. In addition, eight partner meetings were held to feed back information to Alfa as well as validate findings and results. In these meetings, employees at Alfa were encouraged to reflect and give responses on the empirical work in order to check for accuracy [40].

Access was granted to six internal documents to obtain formal information of the organization's size, business, structure, and strategic work with industrial digitalization. These documents emphasize Alfa's vision and core values: responsibility, excellence, and innovation. The three core values were designed and communicated to influence the overall strategic and operational work to provide guidance to employees.

As is often the case with manufacturing industries, Alfa has a hierarchical organizational structure, operating at a centralized office level supported by the business functions. Underneath, each workshop operates as a closed system, working with others if the internal system of supply chain demands so. Alfa consists of seven individual production units. Five of the production units produce and perform maintenance of cutting-edge components of high-quality product parts for the energy sector. Further, these five units manufacture heavy and high-quality products with advanced production processes, and low automation grade with a high amount of manual work such as welding. These five units are also primarily arranged in-job shop layouts with comparatively long production times and crossing production flows. Standard production processes are machining, including milling and turning, and other processes such as cutting, pressing, forming, welding, etc. The additional two production units produce spare parts and new parts on demand through the production process of additive manufacturing. To summarize, all seven units produce advanced, physically large-sized products for a global energy market. However, 
the industrial digitalization of the case-study company may be viewed as scattered since some units of the organization are well advanced while a larger part of the organization is still in the early phases of the industrial digitalization journey.

From a historical perspective, Alfa manufacturing has undergone a change process from being a prototype workshop to moving into series production. Over the years, Alfa has initiated and distributed multiple projects internally labeled as digitalization initiatives, by employees described as attempts to "leverage the possibilities and opportunities of digitalization". The overall aim declared in the visionary documents explicitly states that everything Alfa develops and produces in the long term shall aim towards zero emissions for sustainability.

Furthermore, Alfa has business functions such as IT, digitalization, and human resources (HR) situated globally. These functions define corporate standards and support the overall infrastructure of the company. These functions are at Alfa referred to as "global".

The corporate service group of employees at Alfa consists of a compilation of managers and corporate service employees from the following functions: technical managers, quality mangers, and production, logistics, and business. Furthermore, HR business partners, business administration, business development, and IT and planning are covered in the corporate services. This section of employees has in most cases a higher educational degree and many of them have been working for Alfa for more than 20 years; some of them even longer, starting off as trainees.

Detailed data generation was conducted through 35 semi-structured interviews between the 5 March 2019 and 24 June 2021. All interviews followed an interview guide including themes of questions, such as; "What is the significance and ambition of Industry 4.0 technologies in production (the organization's)?"; "The organization employs what concept(s) to describe digitalization?"; "Does the organization have a meaningful cohesiveness of employed concept(s)?"

Given the explorative approach, the selection of informants was based on a snowball sample [41] to capture different employees within the corporate service section. Towards the end of an interview session, informants were asked to suggest additional informants. Snowball sampling is a valuable method to reach and locate a target group or hidden groups within a case study, giving access to formal and informal social circles, and encouraging involvement in the study since it is often based on trust [42]. However, all informants went through the same criteria of inclusion, i.e., to represent a cross section of employees working with various assignments related to strategic work in corporate services.

Snowball sampling is based on referral sampling where one informant recommends the second who refers to the third and so on, hence the analogy of a snowball [39]. The snowball sampling is a dynamic social process conveyed over time [39]. Given the above, informants spanned multiple functions and included managers, in-house consultants, and technologists, as illustrated in Table 2. Alfa and its informants have been described as transparently as possible without breaking our confidentiality agreement. In total, 35 interviews, each about an hour in length, were conducted either digitally or face-to-face and recorded with confirmed consent (Table 2).

The data collection was an iterative process in which some of the informants participated in several interviews. Likewise, nine meetings with Alfa were set up to report back and confirm information retrieved in the interviews. Due to the iterative process, the data collection process became longitudinal and spanned between March 2019 and November 2021. 
Table 2. Overview of informants, corporate services.

\begin{tabular}{ccc}
\hline Function & $\begin{array}{c}\text { Number of } \\
\text { Informants (I) }\end{array}$ & Duration (Hours) \\
\hline Managers & 24 & 22 \\
Technical managers & 6 & \\
Quality managers & 4 & \\
Production, logistics, and business & 11 & \\
Service functions & 13 & \\
HR business partner & 2 & 31 \\
Business administration, IT & 4 & \\
and planning & 7 & \\
Business development & 35 & \\
Total &
\end{tabular}

\subsection{Data Analysis}

The qualitative approach yielded an analysis of different informants' interpretation of the sensed responsibility and actors' actions around it. To do so, the analytical process followed a thematic analytical approach; "a method for systematically identifying, organizing, and offering insight into patterns of meaning (themes) across a dataset" [43] (p. 57). All collected data were jointly analyzed in several rounds by all authors (see Figure 2) and we thus took an iterative approach following a method of a thematic analysis.

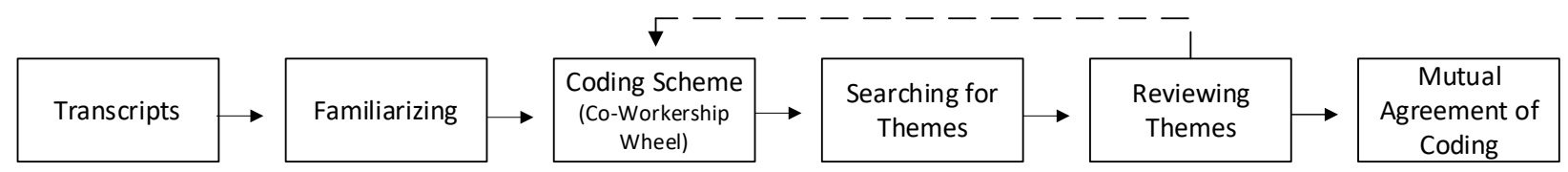

Figure 2. Analytical process.

The data were initially revised to identify excerpts reflecting employee perspectives of industrial digitalization challenges. This familiarizing process with the collected data ( $31 \mathrm{~h}$ of recorded material) resulted in a total of 256 selected excerpts. To narrow the number of excerpts, interview transcripts and field notes were examined to identify statements or actions that reflected employees' perspectives of industrial digitalization. In this step, data were read and sorted into categories based on the data rather than imposed theoretical assumptions [44]. Once all data were examined, 224 excerpts remained.

Then, a second round of analysis followed, identifying challenges related to each of the four conceptual pairs through a coding scheme based on the co-workership wheel: trust and openness, community spirit and cooperation, engagement and meaningfulness, and responsibility and initiative (see Figure 1). This step was to reflect upon whether the determined identification displayed common analytical patterns within each conceptual pair [45]. This round resulted in a total of 57 excerpts scattered across the four conceptual pairs of the co-workership wheel.

The third round in the analytical process was searching for analytical patterns within each conceptual pair. This iterative examination yielded a set of analytical patterns concerning each conceptual pair (see Table 3). When these analytical patterns were identified, the dataset was re-examined and re-coded in a fourth round, using the proposed analytical patterns. This was done to ensure the analytical patterns covered as much data as possible. Once all data were examined, a cross-group analysis followed, comparing the excerpts and the analytical patterns within each conceptual pair to determine whether they reflected common analytical ground [45]. 
Table 3. Overview: analytical patterns within each conceptual pair.

\begin{tabular}{cc}
\hline Conceptual Pairs & Analytical Patterns \\
\hline Trust and & Trust in the system and structure \\
openness & Competence \\
& Adaptability \\
\hline Community spirit and cooperation & Cultural change \\
& Learning \\
& Competence \\
& Cohesive \\
\hline Engagement and meaningfulness & Engagement in digitalization \\
& Shortage of time \\
& Meaningful digitalization \\
\hline & Competence \\
Responsibility and initiative & Resource \\
& Cohesive \\
\hline
\end{tabular}

In this fifth and final iteration, a mutual agreement among the three authors resulted in three overarching analytical themes for navigating industrial digitalization—adaptive culture, learning, and competence (see Table 4).

Table 4. Overview: analytical themes.

\begin{tabular}{ccc}
\hline & Analytical Themes & \\
\hline Adaptive culture & Learning & Competence \\
\hline
\end{tabular}

In the following section, the findings are presented in accordance with the analytical patterns (see Table 3) and the analytical themes (see Table 4).

\section{Research Findings}

A larger set of analytical patterns (13) were found to characterize employees' interpretations of industrial digitalization and its role in Alfa and the challenges postulated (see Table 3). These analytical patterns embodied how employees understood the challenge of industrial digitalization, and how they came to challenge various aspects of their work. The analytical patterns interacted and overlapped within and between the conceptual pairs. The analytical patterns are not believed to be independent. However, for the purpose of discussion, they are distinguished since such a distinction highlights the relevant differences in potential navigation of them. Below, the findings are presented with selected excerpts for each of the four conceptual pairs (see Tables 5-8).

The selected excerpts related to the first conceptual pair, trust and openness, resulted in four analytical patterns: trust in the system and the structure, competence, and adaptability (see Table 5). Analysis of trust in the system and structure demonstrated a culture among employees in which it was hard to build and retain trust towards digital systems. Informants stressed that even if pilots of initiatives were made, the human factors were seldom accounted for in the pilot or finished product, which created a suspicion towards the organizational structure. The second analytical pattern, competence, reflected a need for increased competence in what a digital system affords. Informants described how data output can be inconvenient, thus disbelieved. Furthermore, informants emphasized not having the same level of competence and thus having a hard time trusting each other or the initiatives. The third analytical pattern was adaptability. Informants had a clear and somewhat broad idea of what challenges Alfa faced when adapting to industrial digitalization. Essentially, informants stressed that an overarching vision was needed to reach an openness towards digitalization initiatives. What such a vision would mean for the leadership, structure, and culture of Alfa, or how it would be enacted, was not specifically articulated. 
Table 5. Trust and openness.

\begin{tabular}{|c|c|c|}
\hline Analytical Patterns & ID & Excerpts \\
\hline \multirow{9}{*}{$\begin{array}{l}\text { Trust in the system and } \\
\text { the structure }\end{array}$} & I3 & $\begin{array}{l}\text { "It's also this, that when you have tried to introduce something new here, you } \\
\text { do not dare to trust it [the system] and then it will be undermined in the end." }\end{array}$ \\
\hline & I1 & $\begin{array}{l}\text { "We will never make the system work if we do not follow it: shit in, shit out. } \\
\text { I'm sitting on my hands here. " }\end{array}$ \\
\hline & $\mathrm{I} 27$ & "It has to be correct in our systems, which is not the case right now." \\
\hline & I4 & $\begin{array}{l}\text { "The way we work now, we e-mail what to override the production } \\
\text { scheduling software with, because it [the system] doesn't have time to } \\
\text { update—so we deprioritize ourselves." }\end{array}$ \\
\hline & I4 & $\begin{array}{l}\text { "Sometimes the production card disappears and then you go looking for it. } \\
\text { You don't go into the computer and search for the information. You go around } \\
\text { looking for the piece of paper." }\end{array}$ \\
\hline & $\mathrm{I} 29$ & $\begin{array}{c}\text { "Imagine if we had it all digitalized how good it would have been, but at the } \\
\text { same time, no, it might not have been really that good; look at the problems } \\
\text { that are being created." }\end{array}$ \\
\hline & I4 & $\begin{array}{c}\text { "One piloted [IoT software] on a too small a scale, I think ... I think it was } \\
\text { piloted too little. That's my spontaneous feeling. The system had not really } \\
\text { been understood." }\end{array}$ \\
\hline & I21 & $\begin{array}{l}\text { "You spend more time convincing managers upwards than you spend on the } \\
\text { digital initiative itself." }\end{array}$ \\
\hline & I17 & $\begin{array}{l}\text { "You can push as much top down as you want, but if you don't have any } \\
\text { confidence from the bottom up, it won't work." }\end{array}$ \\
\hline \multirow{2}{*}{ Competence } & I29 & $\begin{array}{l}\text { "It's always uncomfortable when a system reflects reality and the reality looks } \\
\text { this bad. That kind of acceptance is not always a company ready to embrace." }\end{array}$ \\
\hline & I11 & $\begin{array}{l}\text { "It is also a journey of maturity. There is no big abyss between us, but you } \\
\text { have slightly different understandings. We're looking a little bit more long } \\
\text { term while the first line is looking a little more operationally." }\end{array}$ \\
\hline \multirow{5}{*}{ Adaptability } & I5 & $\begin{array}{c}\text { "It's fun to have some tablets in the production. ... [However] I haven't seen } \\
\text { any underlying ideas. It is more [important] that one can show } \\
\text { that you have it [tablets]." }\end{array}$ \\
\hline & I12 & $\begin{array}{l}\text { "We are too vague in our communication with our employees and especially } \\
\text { when it comes to digitalization." }\end{array}$ \\
\hline & I35 & $\begin{array}{l}\text { "It's about getting employees to understand the big picture: where are we } \\
\text { going and understanding its [digitalization's] role in the production flow ... } \\
\text { one must visualize the production flow to understand its role in this." }\end{array}$ \\
\hline & $\mathrm{I} 10$ & $\begin{array}{c}\text { "I need to see the whole picture in order to see the benefits, but I don't need to } \\
\text { understand the details." }\end{array}$ \\
\hline & I26 & $\begin{array}{l}\text { "I think it [leadership] needs to be very clear and that everyone is working in } \\
\text { the same direction ... production is best served by the fact that we are going in } \\
\text { the same direction and that it is very open. ... we want to know what's going } \\
\text { on and feel as a part of it." }\end{array}$ \\
\hline
\end{tabular}

The selected excerpts related to the second conceptual pair, community spirit and cooperation, resulted in four analytical patterns: cultural change, learning, competence, cohesiveness (see Table 6).

Cultural change. An important aspect of understanding the challenges of industrial digitalization is understanding how to appropriate and deploy its effects effectively. Such knowledge was interpreted by the informants as a challenge in the collective structure. Lack of interest, communication, and competence were identified as hindering factors embedded in the collective structure. The informants in this case study interpreted that they received little or no official resources for learning how to adapt or get acquainted with industrial 
digitalization. Some informants described the learning process as a lonely journey and thus some informants had limited knowledge of initiatives. Other informants had ideas about initiatives, but these were either misinterpreted in what competence was needed, or the initiatives were merely focused on the need for tablets or computers with an incomplete vision of the applicability. The final analytical pattern, cohesiveness, demonstrated the lack of formal and informal connection between functions. In addition, coordination of strategic work was interpreted as missing; that is, because an incremental change process was missing, many initiatives were left to be dealt with by a few of the informants.

Table 6. Community spirit and cooperation.

\begin{tabular}{|c|c|c|}
\hline Analytical Patterns & ID & Excerpts \\
\hline \multirow{2}{*}{ Cultural Change } & I2 & $\begin{array}{l}\text { "Historically, we haven't been that interested. We think we've done pretty well on our } \\
\text { own. But with things like this [digitalization] we don't. We don't have the resources." }\end{array}$ \\
\hline & I6 & $\begin{array}{l}\text { "Regarding competence and communication: after all, you should be able to get } \\
\text { support from any group by sitting by the neighbouring desk or door to door next by." }\end{array}$ \\
\hline \multirow{3}{*}{ Learning } & I7 & $\begin{array}{c}\text { "Sometimes I think you kind of need to try it out. Sometimes it gets a bit wrong. Then } \\
\text { you must back off. Maybe we have slightly different views there." }\end{array}$ \\
\hline & I17 & $\begin{array}{l}\text { "Maybe the problem is that one has done oneself a disservice and called it } \\
\text { digitalization. If you had just presented it as this is another business development } \\
\text { project, you might have had other references and other possibilities." }\end{array}$ \\
\hline & I8 & $\begin{array}{l}\text { "Try and translate the goals into what it means for us to meet the requirements. You } \\
\text { take a little step every day. You can't take a big step. ... There are risks involved." }\end{array}$ \\
\hline \multirow{4}{*}{ Competence } & I8 & $\begin{array}{l}\text { "Optimally, it would fit like a glove, but there are different digitalization strategies } \\
\text { coming from above. But as I said, it has to be put into practice at an understandable } \\
\text { level by the employees." }\end{array}$ \\
\hline & I8 & $\begin{array}{c}\text { "Digitalization probably has different meanings for different people. But when you } \\
\text { come up with these overall plans, it comes to such an abstract level that it does not } \\
\text { become gripping for the employees." }\end{array}$ \\
\hline & $\mathrm{I} 23$ & $\begin{array}{l}\text { "Within manufacturing in general, it may be difficult to separate digitalization from } \\
\text { digitization or just like IT in general." }\end{array}$ \\
\hline & $\mathrm{I} 10$ & $\begin{array}{c}\text { "Most operators don't have their own computers, tablets or anything like that. So, we } \\
\text { still have a bit of a walk to take there... We're still kind of printing the order } \\
\text { statements on paper. I think it's really weird in 2020." }\end{array}$ \\
\hline \multirow{7}{*}{ Cohesive } & I10 & $\begin{array}{c}\text { "Our boss is trying to keep us together so we're able to work together. But otherwise, } \\
\text { there has been a lot of spread between different functions how digitalized you are. I } \\
\text { haven't seen a holistic approach to the whole site." }\end{array}$ \\
\hline & I11 & $\begin{array}{l}\text { "I couldn't keep all the roadmaps up to date. They became out of date after a while } \\
\text { because we didn't look at them." }\end{array}$ \\
\hline & $\mathrm{I} 13$ & $\begin{array}{c}\text { "Where do we store different types of data? We haven't quite sorted that out yet. I } \\
\text { think that should be done more overall." }\end{array}$ \\
\hline & $\mathrm{I} 13$ & $\begin{array}{l}\text { "But there will be a bit more of islands where we create automation and robot } \\
\text { solutions and not fully integrated solutions." }\end{array}$ \\
\hline & I17 & $\begin{array}{l}\text { "One wants to do a lot on short-time small projects that give pay-off at once and it } \\
\text { doesn't always rhyme with what digitalization actually is." }\end{array}$ \\
\hline & I6 & $\begin{array}{c}\text { "It's a project that's on John's [fictive name] desk and it lives a little in the shadows to } \\
\text { the day-to-day operations." }\end{array}$ \\
\hline & I8 & $\begin{array}{l}\text { "Everything is business driven and you almost have to convince [the } \\
\text { management/the organization/who?] that this [digital initiative] is good." }\end{array}$ \\
\hline
\end{tabular}

Selected excerpts related to the third conceptual pair, engagement and meaningfulness, are categorized in three analytical patterns: engagement for industrial digitalization, time shortage, and meaningful industrial digitalization (see Table 7). 
Table 7. Engagement and meaningfulness.

\begin{tabular}{|c|c|c|}
\hline Analytical Patterns & ID & Excerpts \\
\hline \multirow{7}{*}{$\begin{array}{l}\text { Engagement for industrial } \\
\text { digitalization }\end{array}$} & I4 & "First and foremost, I think you have to get the employees interested in digitalization." \\
\hline & $\mathrm{I} 22$ & $\begin{array}{l}\text { "It is no longer possible just to talk about it, you really have to hold on and rave over } \\
\text { digitalization-otherwise it will not happen!" }\end{array}$ \\
\hline & I24 & "It is not a hobby and it is not a playhouse ... it is serious now!" \\
\hline & I18 & "We are in a production situation that we cannot plan ourselves out of." \\
\hline & I31 & $\begin{array}{c}\text { "We see great opportunities to collect data in a short time and spend time doing } \\
\text { analyses instead of spending time collecting data from very different systems, as we } \\
\text { have it today." }\end{array}$ \\
\hline & $\mathrm{I} 2$ & $\begin{array}{l}\text { "... and then the production managers are the next team to be persuaded believers } \\
\text { who understand that this [digitalization] is what we are going to do. If that step is not } \\
\text { completed, it will be extremely difficult to get anything to happen." }\end{array}$ \\
\hline & I6 & $\begin{array}{l}\text { "One would like to have time to sit down and do something good from scratch, but } \\
\text { there does not seem to be time. It is like running next to the bike and not having time to } \\
\text { jump on it." }\end{array}$ \\
\hline \multirow{3}{*}{ Time shortage } & $\mathrm{I} 2$ & $\begin{array}{l}\text { "I do not think we understand this journey of change-that it has begun! We are too } \\
\text { busy doing what we always do." }\end{array}$ \\
\hline & I15 & $\begin{array}{l}\text { "We dig where we stand! We have to look up and ahead!" [They are stuck in one place } \\
\text { and need to increase the view (holistically) to move forward.] }\end{array}$ \\
\hline & I7 & $\begin{array}{l}\text { "Sometimes it feels like this: 'At least we have published many PowerPoints'. But when } \\
\text { you are in the middle of it, you wonder-is this progress?" }\end{array}$ \\
\hline \multirow{4}{*}{$\begin{array}{l}\text { Meaningful industrial } \\
\text { digitalization }\end{array}$} & I5 & $\begin{array}{c}\text { "I do not grasp it! I was attending a workshop and did not really understand that it was } \\
\text { about digitalization!" }\end{array}$ \\
\hline & I3 & $\begin{array}{c}\text { "Should we use the individuals' private smartphones out there [in production] or } \\
\text { should we give them smart watches that measure how they move. Or maybe those } \\
\text { vision cameras?" }\end{array}$ \\
\hline & I1 & $\begin{array}{l}\text { "It feels like the only thing we achieve is that we make texts electronic. I need more } \\
\text { digital features out of it [the digitalization]. ... that is what I had expected." }\end{array}$ \\
\hline & I19 & $\begin{array}{l}\text { "If you really want to get into Industry } 4.0 \text {, then we need to look into machines and } \\
\text { such with instant feedback. We have a lathe from } 1952 . \text { There is a challenge also there." }\end{array}$ \\
\hline
\end{tabular}

Analysis of the engagement in industrial digitalization demonstrated the importance of generating interest among employees, to be able to identify opportunities, and the potential impacts of industrial digitalization, while at the same time realizing that now was the time to face industrial digitalization. Informants stressed that all levels of the organization needed to be included and to engage 'believers' to make things happen.

The excerpts about the second pattern—time shortage - point out informants' views of perceived shortcomings regarding lack of time and focus on industrial digitalization. The challenge is to keep regular production going while at the same time understand and plan for ongoing or future industrial digitalization.

The last analytical pattern, meaningful industrial digitalization, includes excerpts in which informants do not understand or worry about what digitalization may mean for the organization, what kind of digital devices are needed for individuals in the production, what are the benefits of a digitalized production, and how industrial digitalization may be compatible with an older traditional machine park with much manual work.

Selected excerpts related to the fourth conceptual pair, responsibility and initiative, are categorized in four analytical patterns: competence, resources, and cohesiveness (see Table 8). 
Table 8. Responsibility and initiative.

\begin{tabular}{|c|c|c|}
\hline Analytical Pattern & ID & Excerpts \\
\hline \multirow[t]{3}{*}{ Competence } & I10 & "Now it is so that I tag along those who are interested [in industrial digitalization]." \\
\hline & I5 & $\begin{array}{c}\text { "I always ask what problem we solve now and after the third time I ask, I usually don't get to be } \\
\text { involved any more." }\end{array}$ \\
\hline & I11 & $\begin{array}{l}\text { "Some people are interested in this topic, they are interested in digitalization both privately and at } \\
\text { work. They pick up much faster. Somewhere you have to find what the minimum level is. What } \\
\text { skills and knowledge do we need among our employees? At the same time, we must not hinder } \\
\text { those who are passionate about it." }\end{array}$ \\
\hline \multirow[t]{4}{*}{ Resources } & I15 & $\begin{array}{l}\text { "It's a small challenge that John [fictive name] is quitting. He's passionate about digitalization and } \\
\text { things like that. Now that he's disappearing we've got to try to continue on his parole there." }\end{array}$ \\
\hline & I6 & "We can't rely on charity." \\
\hline & I17 & $\begin{array}{l}\text { "I don't think it's an optimal set-up at the moment because it's enthusiasts who lead the initatives } \\
\text { here and there, and thus it will not be a whole." }\end{array}$ \\
\hline & I5 & $\begin{array}{l}\text { "I have been given the role of working with digitalization, but there is no budget and } \\
\text { no framework." }\end{array}$ \\
\hline \multirow[t]{4}{*}{ Cohesiveness } & I13 & $\begin{array}{l}\text { "Whether an initiative comes from above or below doesn't matter. It goes into a process where we } \\
\text { produce a buisness case and check the budget [and present] it in a forum where all managers at my } \\
\text { level and above take a stand." }\end{array}$ \\
\hline & I7 & $\begin{array}{c}\text { "Even though I didn't know all the lines of argument [in the business case], I found out how they } \\
\text { [initatives] would be pushed to get a decision. Then there were further decision-making paths } \\
\text { afterwards. That was frustrating." }\end{array}$ \\
\hline & I9 & $\begin{array}{l}\text { "Then there is a lack of knowledge about how to fill out the template [for business cases]. That's } \\
\text { why you need the help of a business developer." }\end{array}$ \\
\hline & I11 & $\begin{array}{c}\text { "I have no designated digitalization manager in my management team, it is a } \\
\text { shared responsibility." }\end{array}$ \\
\hline
\end{tabular}

The excerpts in the analytical pattern sorted as competence demonstrated the need for a common level of understanding of I4.0 technologies to take initiative and be willing to seize responsibility. Moreover, not having a mutual lowest level of competence was interpreted by some informants as creating a need to question and dispute initiatives.

The third analytical pattern-resources — demonstrated informants' hardship and ambiguity when communicating applying for resources for an initiative. Informants interpreted both soft resources (employees and skills, etc.) and hard resources (money, time, etc.) as important to distribute so the responsibility of industrial digitalization was allocated to the collective rather than risking it being outsourced to a single individual.

The third and final pattern-cohesiveness-includes excerpts in which informants express that the lack of harmonization in the organizational structure has removed the employees' allowance for taking responsibility for industrial digitalization initiatives. Informants emphasized the vulnerability of lacking cohesiveness when building responsibility and initiatives regarding I4.0 technologies.

Given the above, three analytical themes for navigating industrial digitalizationadaptive culture, learning, and competence-were found to overarch all analytical patterns (see Table 4).

Adaptive culture refers to the challenge of organizing and continuously supporting industrial digitalization initiatives in a flexible style while understanding organizational capabilities and collective structures. Informants regularly spoke of an indistinct culture within the organization which allowed for formulating and reformulating the capabilities that would facilitate industrial digitalization. At the time, such a capability did not exist within Alfa, either in the organization as a whole or at the local production units. Many of the informants' interpretations around industrial digitalization exposed unsynchronized actions that were reflected in distrust in the system and structure, adaptability, engagement, 
and believed meaningfulness. That is, informants were caught up with the advanced capabilities of I4.0 technologies rather than focused on its role to some specific organizational end. This was illustrated by Informant 3 stressing that an adaptive culture is of high importance:

"If you ask me, it's the culture. If you ask them why one does not follow the production planning system ... Somewhere it is a lack in courage, and you dare not trust the system. I feel like I have to make the system so incredibly transparent and good for people, so there's no doubt about how to get it up and running. So, you have to go berserk and bend yourself around to get through. And there's something curious here. It is an aspect of not daring to let it [the old way] go. And if I suggest it then I'll be assassinated." (I3)

Learning refers to informants' views of how their organization acquired and implemented initiatives of industrial digitalization. Learning includes their understanding of the motivation or vision behind organizing and continuously supporting decisions and the likeliness of benefiting the organization. When employees were asked how they experienced implementing I4.0 technology, they tended to focus on the technical aspects in the form of a business case. The potential revenue and success were stressed; however, social aspects were left out. In other words, informants lacked the time and focus for trial and error. All informants generally described this assumption as:

"It's a problem when everything is going too fast, and you don't have time to learn." (I33)

Other informants had similar reactions but observed the space of growth more directly:

"It also needs to be coaching to allow the individuals to grow." (I34)

Competence refers to informants' interpretation of what understanding is required for the individual and what knowledge is required at the collective's lowest level. The informants in this study argued that they had little or no required competence for navigating the challenges of industrial digitalization. When they were interviewed, many reported a mixed understanding of how I4.0 technologies could be applied and how such applications could be dealt with, and by whom. Furthermore, many of the informants did not know who had the formal responsibility for industrial digitalization or related initiatives in the organization. In the absence of competence, informants stressed that it was important to build a common ground:

"My idea is that if you are going to have speed on digitalization it is probably the most effective to do many small [initiatives], a little try it out, so employees get to try it out and learn what can be done. One of the challenges I have seen in digitalization is that we as business managers must have a certain type of competence when we want to realize the digitalization projects." (I11)

\section{Discussion}

This study approached the challenges of industrial digitalization through an employee perspective by applying the co-workership wheel [16]. Findings indicate that to face industrial digitalization, contemporary manufacturing industries need to focus on the human-centric perspective to sense and seize the prospects of I4.0 technologies. This understanding is in line with recent reports by the European Union [4,6] and recent research stressing the importance of the human factor in digitalizing production $[5,11,27]$.

The human-centric perspective is also shown in the capabilities-adaptive culture, learning, and competence-identified to be needed by contemporary organizations when navigating the challenges industrial digitalization poses [12]. The findings herein state that contemporary manufacturing industry has a technocentric perspective of industrial digitalization in which I4.0 technologies are not fully synchronized with the overall production. Organizations continuously adjust to how I4.0 technologies extend the function of work routines. However, the cognition of how I4.0 technologies affect the overall organization are not considered or accounted for and related to social aspects of an organization [9]. Corresponding to earlier research, this case study also identified the importance of applying 
a holistic view focusing on human, social, and cultural aspects when organizations are moving towards industrial digitalization $[1,7,11,25]$. This is seen as crucial for transforming existing production while maintaining daily operational capacity. As shown at Alfa, when an organization changes the cognition of diverse perspectives it is institutionalized and manifested through culture. However, once the understanding is institutionalized it tends to produce organizational inertia - a state of organizational stagnation [9]. This may also prevent an organization from negotiating a changing environment, i.e., industrial digitalization, potentially leading to an unwanted regression of change towards industrial digitalization. Again, this illustrates the need to emphasize human, social, and cultural aspects when navigating the challenges of industrial digitalization.

We argue that for organizations to face challenges and take responsibility for industrial digitalization with a human-centric perspective, the following themes must be accounted for in organizing and continuously supporting concerns: an adaptive culture, learning, and competence (see Figure 3).

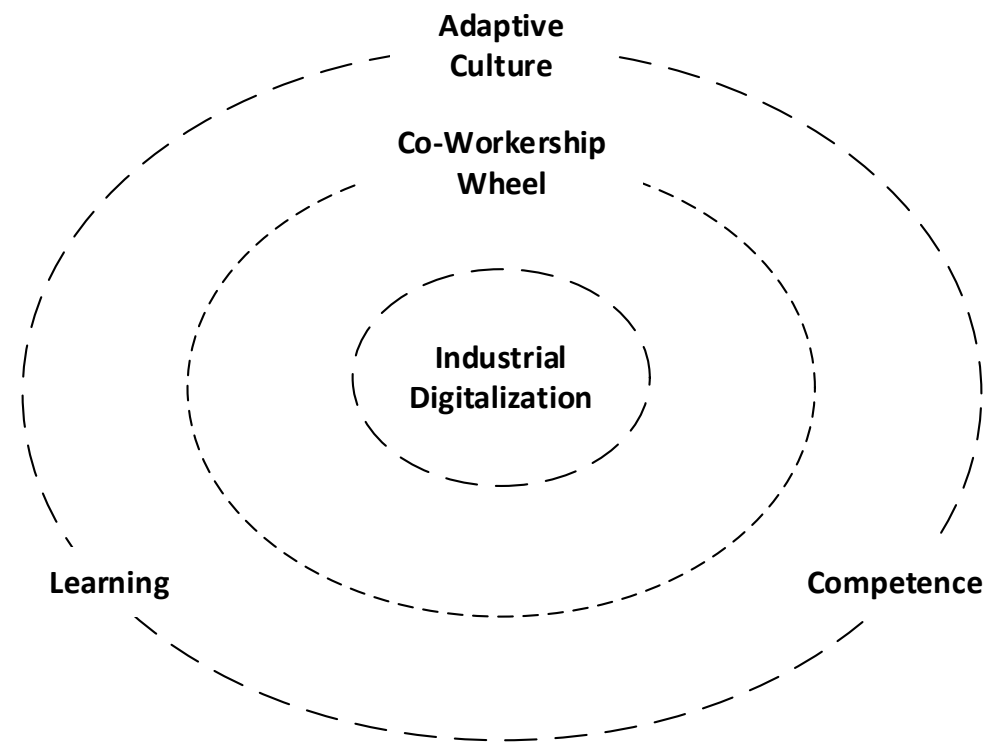

Figure 3. Illustration of a human-centric industrial digitalization.

Organizing and continuously supporting an adaptive culture. Employees sometimes pass on responsibility to others, make excuses to avoid engagement, or lack confidence in the digitalization process since it is unclear where the responsibility for digitalization lies. Hence, it could be argued that there is a lack of guiding norms, beliefs, and routines for facing industrial digitalization $[7,16,17]$. As such, this affects community spirit and trust within the organization [16] since one of the challenges of organizing and continuously supporting concerns of industrial digitalization in a flexible style and, in addition, formulating an adaptive culture that deals with potential negative cognitions such as fear, low self-esteem, and scapegoating. If not, understanding an organization's capabilities may become unsynchronized with employees' abilities. As presented in the findings, cognition plays an important part in anchoring Industry 4.0 technologies to existing production systems. Several examples show how Alfa tested different I4.0 technologies for production planning and control of production, although they did not always follow it all the way through and sometimes returned to manual planning, applying, e.g., Excel. Characteristically those digital initiatives depended on an individual enthusiast with a sole drive. The organizational capability of navigating industrial digitalization hence risk becoming reliant of the ability of enthusiasts.

Because of this inability to follow through, intense uncertainty arises. To this, Alfa has responded by encouraging the organization to create initiatives that easily could be copied to other parts of the organization-the innovation and progress of I4.0 technologies 
were forced into an initialized frame. However, though this response is not necessarily inherently negative, the cognition of how I4.0 technologies affect the norms, beliefs, and routines was neither being negotiated nor accounted for.

Organizing and continuously supporting learning. This domain allows us to explain that although an adaptive culture is essential, it is not all. For example, a certain amount of backlash in change towards industrial digitalization must be allowed for and thus learning should be prioritized [9]. Contradictory outcomes, due to different interpretations of I4.0 technologies, are not only due to technological misfits, but are also affected by organizational norms, beliefs, and routines [26]. Suggesting that a certain amount of organizational backlash in change towards industrial digitalization must be allowed for and thus learning should be prioritized [9]. Hence, the appropriation of interpretations needs to be openly communicated, likewise the acceptance of misfits [16]. Alfa's employees, in contrast, formulated a fear of making faulty decisions. As such, employees rather did nothing than risked doing wrong. In addition, backlashes were neither accounted for nor anticipated. When backlashes did occur, the change process was turned down since there was no time for learning what went wrong. The day-to-day operational work overrides the long-term vision. The "fear of doing wrong" thus forms a powerful jargon that is not stimulating learning for industrial digitalization.

Organizing and continuously supporting competence. Alfa employees repeatedly stated that there was no time, place, or strategy for competence development, contrasting earlier research on the importance of continuing competence development addressing industrial digitalization [26,33]. Most of Alfa's employees had been employed for a long time or were considered to be of high age, and thus competence development was not seen as relevant. According to employees, the older workforce was more costly to focus on than recruiting a younger workforce to address industrial digitalization. Hence, the younger generation of employees was considered responsible for sensing and seizing I4.0 technologies.

Alfa has not prioritized organizing and continuously supporting digital competence throughout the organization, which has resulted in lack of interest among the employees and passing responsibility to enthusiasts with a sole drive for digital initiatives.

Applying a human-centric perspective that considers digital upskilling and re-skilling employees is a crucial prerequisite for navigating industrial digitalization.

\subsection{Research Contribution}

This study contributes to the research on organizing and continuously supporting industrial digitalization by exploring the perspectives of manufacturing organizations employees and their impact on navigating the challenges of industrial digitalization. The challenges were identified to be three overarching analytical themes related to the humancentric perspective on organizing and continuously supporting industrial digitalization: an adaptive culture, learning, and competence.

\subsection{Implications for Practice}

We argue that the identified analytical themes have useful implications for manufacturing organizations' strategic imperative. For example, a great technocentric focus results in outcomes that may deviate from the anticipated vision. The three analytical themes offer a human-centric approach to face and navigate industrial digitalization in a sustainable and inclusive manner.

\subsection{Implications for Further Research}

While the three analytical themes are individually understood, they are also intertwined. We emphasize that the three identified analytical themes extend earlier work focusing on the human-centric perspective. In particular, the analytical themes are useful when trying to understand how organizations face and navigate challenges and how responsibility is accounted for. For example, while a technocentric approach may explain 
the adaptive issues of navigating industrial digitalization, the identified analytical themes have implications for organizations' strategic imperative.

Further research is encouraged to focus on the three identified analytical themes from the perspective of operators to further explore the issue of responsibility related to industrial digitalization.

\section{Conclusions}

By applying an employee perspective, this study contributes to exploring how organizations face challenges and take responsibility for industrial digitalization. The study provides an in-depth case study analysis of employees' perspectives using the co-workership wheel to identify challenges related to industrial digitalization. Lessons learned from this longitudinal explorative case study indicate the importance of an adaptive culture and a focus on learning and competence while navigating industrial digitalization. Thus, the following analytical themes were identified as vital to organize and continuously support manufacturing organizations navigating the challenges of industrial digitalization:

(i) Adaptive culture

(ii) Learning

(iii) Competence

Applying a human-centric perspective that considers the prerequisites of an adaptive culture, learning, and competence of employees is herein argued to be crucial for navigating industrial digitalization. As the challenges of industrial digitalization are not typically discussed or articulated, they may, as we saw in the case of Alfa, result in unwanted misaligned actions.

The conceptualization of adaptive culture, learning, and competence also provides a means for influencing the organizational development and implementation process as industrial digitalization proceeds. It may also provide insight into the potential source of incongruence among employees; different incongruences may provide different characteristics of challenges or opportunities and hence the nature of navigation may shift over time. That is, distinguishing between incongruences due to structural, cultural, or social (human) factors may give more information to organize and continuously support an organization. For example, realizing the need for a more human-centric approach navigating industrial digitalization could reframe industrial digitalization to an incremental change rather than radical and threatening as anticipated by employees in the given case.

\section{Limitations and Future Work}

There may be limitations due to the single case study approach; however, the intention was to bring forth an in-depth case study analysis contributing to the human-centric perspective and the emerging I5.0 research. To further develop the findings, the existing case study is planned to be enriched by comparative analysis including of a structured sample selection of further staff functions such as shop-floor level and manufacturing engineers. Furthermore, future studies are encouraged to cover multiple cases or even different business sectors to examine what actions respective analytical themes include and how such actions can be managed to transform an organization navigating industrial digitalization. The analytical themes herein presented may be particularly important in the case of dealing with industrial digitalization and transforming an organization accordingly. Understanding adaptive culture, learning, and competence also have implications for the practice of strategic work itself: in professionals' way of making sense of and employees ability to partake in industrial digitalization initiatives.

Author Contributions: Conceptualization, L.C.; methodology, L.C., A.K.O., and K.E.; validation, L.C., A.K.O., and K.E.; formal analysis, L.C., A.K.O., and K.E.; investigation, L.C., A.K.O., and K.E.; data curation, L.C., A.K.O., and K.E.; writing-original draft preparation, L.C., A.K.O., and K.E.; writing-review and editing, L.C., A.K.O., and K.E.; visualization, L.C.; supervision, A.K.O.; project 
administration, A.K.O.; funding acquisition, K.E. All authors have read and agreed to the published version of the manuscript.

Funding: This research was supported by the Swedish Knowledge Foundation Grant no. 202000 350*and University West Sweden.

Institutional Review Board Statement: Not applicable.

Informed Consent Statement: Informed consent was obtained from all subjects involved in the study. Data Availability Statement: Not applicable.

Acknowledgments: The study was carried out within the AHIL-project, Artificial and Human Intelligence through Learning (2020-2022), funded by the Swedish Knowledge Foundation and University West Sweden. We appreciate the assistance provided in six interviews by Monika Hattinger, University West Sweden.

Conflicts of Interest: The authors declare no conflict of interest.

\section{References}

1. Kane, G.C.; Palmer, D.; Phillips, A.N.; Kiron, D.; Buckley, N. Strategy, Not Technology, Drives Digital Transformation; MIT Sloan Management Review and Deloitte University Press: New York, NY, USA, 2015.

2. Chanias, S.; Hess, T. Understanding Digital Transformation Strategy Formation: Insights from Europe's Automotive Industry Mastering Digital Transformation: The Path of a Financial Services Provider towards a Digital Transformation Strategy View Project Bavarian Research Instit. In Proceedings of the PACIS 2016, Chiayi, Taiwan, 27 June-1 July 2016.

3. Santos, G.; Sá, J.C.; Félix, M.J.; Barreto, L.; Carvalho, F.; Doiro, M.; Zgodavová, K.; Stefanović, M. New Needed Quality Management Skills for Quality Managers 4.0. Sustainability 2021, 13, 6149. [CrossRef]

4. Breque, M.; De Nul, L.; Petridis, A. Industry 5.0-Towards a Sustainable, Humancentric and Resilient European Industry; European Commission: Brussels, Belgium, 2021. [CrossRef]

5. Schönborn, G.; Berlin, C.; Pinzone, M.; Hanisch, C.; Georgoulias, K.; Lanz, M. Why Social Sustainability Counts: The Impact of Corporate Social Sustainability Culture on Financial Success. Sustain. Prod. Consum. 2019, 17, 1-10. [CrossRef]

6. Müller, J. Enabling Technologies for Industry 5.0-Results of a Workshop with Europe's Technology Leaders; European Commission: Brussels, Belgium, 2020. [CrossRef]

7. Parviainen, P.; Tihinen, M.; Kääriäinen, J.; Teppola, S. Tackling the Digitalization Challenge: How to Benefit from Digitalization in Practice. Int. J. Inf. Syst. Proj. Manag. 2017, 5, 63-77.

8. Gillam, S.; Cosford, P. Organisational Structure. In Leadership and Management for Doctors in Training; CRC Press: Boca Raton, FL, USA, 2021; pp. 26-31. [CrossRef]

9. Björkdahl, J. Strategies for Digitalization in Manufacturing Firms. Calif. Manag. Rev. 2020, 62, 17-36. [CrossRef]

10. Benešová, A.; Tupa, J. Requirements for Education and Qualification of People in Industry 4.0. Procedia Manuf. 2017, 11, 2195-2202. [CrossRef]

11. Nahavandi, S. Industry 5.0-a Human-Centric Solution. Sustainability 2019, 11, 4371. [CrossRef]

12. Eriksson, K.; Hendberg, T. A Case Study Initiating Discrete Event Simulation as a Tool for Decision Making in I4.0 Manufacturing. In Decision Support Systems, Analytics and Technologies in Response to Global Crisis Management; Jayawickrama, U., Delias, P., Escobar, M.T., Papathanasiou, J., Eds.; Springer: Cham, Switzerland, 2021; Volume 414.

13. Orlikowski, W.J.; Gash, D.C. Technological Frames: Making Sense of Information Technology in Organizations; ACM Transactions on Information Systems (TOIS): New York, NY, USA, 1994; Volume 12, pp. 174-207.

14. Blštáková, J.; Joniaková, Z.; Jankelová, N.; Stachová, K.; Stacho, Z. Reflection of Digitalization on Business Values: The Results of Examining Values of People Management in a Digital Age. Sustainability 2020, 12, 5202. [CrossRef]

15. Warner, K.S.R.; Wäger, M. Building Dynamic Capabilities for Digital Transformation: An Ongoing Process of Strategic Renewal. Long Range Plann. 2019, 52, 326-349. [CrossRef]

16. Andersson, T.; Stockhult, H.; Tengblad, S. Strategies for Co-Workership Retention. Hum. Resour. Dev. Int. 2020, 1-21. [CrossRef]

17. Brunetti, F.; Matt, D.T.; Bonfanti, A.; De Longhi, A.; Pedrini, G.; Orzes, G. Digital Transformation Challenges: Strategies Emerging from a Multi-Stakeholder Approach. TQM J. 2020, 32, 697-724. [CrossRef]

18. Kilhammar, K.; Ellström, E. Co-Workership in Practice: A Study of Two Swedish Organizations. Hum. Resour. Dev. Int. 2015, 18, 328-345. [CrossRef]

19. Andersson, T.; Crevani, L.; Zetterquist-Eriksson, U.; Tengblad, S. Chefskap, Ledarskap Och Medarbetarskap, 1st ed.; Studentlitteratur: Lund, Swedish, 2020.

20. Helfat, C.E.; Finkelstein, S.; Mitchell, W.; Peteraf, M.A.; Singh, H.; Teece, D.J.; Winter, S.G. Dynamic Capabilities: Understanding Strategic Change In Oranizations; Blackwell Publishing Ltd.: Oxford, UK, 2007.

21. Kohli, R.; Melville, N.P. Digital Innovation: A Review and Synthesis. Inf. Syst. J. 2019, 29, 200-223. [CrossRef]

22. Moon, T. Organizational Cultural Intelligence: Dynamic Capability Perspective. Gr. Organ. Manag. 2010, 35, 456-493. [CrossRef] 
23. Osterrieder, P.; Budde, L.; Friedli, T. The Smart Factory as a Key Construct of Industry 4.0: A Systematic Literature Review. Int. J. Prod. Econ. 2020, 221, 107476. [CrossRef]

24. Vial, G. Understanding Digital Transformation: A Review and a Research Agenda. J. Strateg. Inf. Syst. 2019, 28, 118-144. [CrossRef]

25. Mandal, P.; Mukhopadhyay, S.; Bagchi, K. The Impact of Organisational Strategy, Culture, People and Technology Management on Organisational Practic and Performance: An Empirical Analysis. Inf. Syst. Chang. Manag. 2012, 6, 160-176.

26. Eriksson, K.; Bränneby, E.; Hagelin, M. An Educational Model for Competence Development within Simulation and Technologies for Industry 4.0. In Proceedings of the Winter Simulation Conference, Phoenix, AZ, USA, 15-17 December 2021.

27. Miceli, A.; Hagen, B.; Riccardi, M.P.; Sotti, F.; Settembre-Blundo, D. Thriving, Not Just Surviving in Changing Times: How Sustainability, Agility and Digitalization Intertwine with Organizational Resilience. Sustainability 2021, 13, 2052. [CrossRef]

28. Weick, K.E.; Quinn, R.E. Organizational Change and Development. Annu. Rev. Psychol. 1999, 50, 361-386. [CrossRef]

29. Costello, J.; Plester, B. The Impact of Organisational Culture and Dynamic Capabilities on Learning Evaluation: An Interpretive Analysis. Int. J. Learn. Chang. 2020, 12, 476-497. [CrossRef]

30. Isensee, C.; Teuteberg, F.; Griese, K.M.; Topi, C. The Relationship between Organizational Culture, Sustainability, and Digitalization in SMEs: A Systematic Review. J. Clean. Prod. 2020, 275, 122944. [CrossRef]

31. Bastardoz, N.; Van Vugt, M. The Nature of Followership: Evolutionary Analysis and Review. Leadersh. Q. 2019, 30 , 81-95. [CrossRef]

32. Kilhammar, K. Idén Om Medarbetarskap: En Studie Av En Idés Resa in i Och Genom Två Organisationer. Ph.D. Thesis, Institutionen för Beteendevetenskap och Lärande, Linköping, Sweden, 2011.

33. Paschek, D.; Mocan, A.; Draghici, A. Industry 5.0-The Expected Impact of next Industrial Revolution. In Proceedings of Thriving on Future Education, Industry, Business, and Society, Proceedings of the MakeLearn and TIIM International Conference, Piran, Slovenia, 15-17 May 2019; pp. 125-132.

34. Hess, T.; Benlian, A.; Matt, C.; Wiesböck, F. Options for Formulating a Digital Transformation Strategy. MIS Q. Exec. 2016, 15, 123-139. [CrossRef]

35. Hallin, A.; Crevani, L.; Ivory, C.; Mörndal, M. Digitalisation and Work-Sociomaterial Entanglements in Steel Production. In Digitalization: Information Technology, Knowledge and Sustainability; Nordisk Företagsekonomisk Förening: Bodø, Norway, 2017; pp. 23-25.

36. Launberg, A. Digitalisering i Organisation Och Arbete Nya Förutsättningar För Svenska Företag Inom Metalliska Material; Mälardalen University: Västerås, Sweden, 2017.

37. Ekanem, I. "Insider Accounts": A Qualitative Research Method for Small Firms. J. Small Bus. Enterp. Dev. 2007, 14, 105-117. [CrossRef]

38. Yin, R.K. Case Study Research and Applications, 6th ed.; Sage Publications: New York, NY, USA, 2018.

39. Olsson, A.K.; Bernhard, I.; Arvemo, T.; Snis, U.L. A Conceptual Model for University-Society Research Collaboration Facilitating Societal Impact for Local Innovation. Univ. Res. Collab. 2020, 24, 1335-1353. [CrossRef]

40. Torrance, H. Triangulation, Respondent Validation, and Democratic Participation in Mixed Methods Research. J. Mix. Methods Res. 2012, 6, 111-123. [CrossRef]

41. Noy, C. Sampling Knowledge: The Hermeneutics of Snowball Sampling in Qualitative Research. Int. J. Soc. Res. Methodol. 2008, 11, 327-344. [CrossRef]

42. Atkinson, R.; Flint, J. Accessing Hidden and Hard-to-Reach Populations: Snowball Research Strategies. Soc. Res. Updat. 2001, $33,1-4$

43. Braun, V.; Clarke, V. Thematic Analysis. In Handbook of Research Methods in Psychology; Cooper, H., Camic, P.M., Long, D.L., Panter, A.T., Rindskopf, D., Sher, K.J., Eds.; American Psychological Association: Washington, WA, USA, 2012; Volume 2, pp. 57-71. [CrossRef]

44. Braun, V.; Clarke, V. Using Thematic Analysis in Psychology. Qual. Res. Psychol. 2006, 3, 77-101. [CrossRef]

45. Alvesson, M.; Kärreman, D. Constructing Mystery: Empirical Matters in Theory Development. Acad. Manag. Rev. 2007, 32, 1265-1281. [CrossRef] 